\title{
Establishment of China's Tax-Concerned Information Cooperation and Sharing Mechanism from the International Perspective
}

\author{
Wang $\mathrm{Li}$ \\ School of Finance and Public Management, \\ Yunnan University of Finance and Economics,Kunming, Yunnan,China \\ 2962648413@qq.com
}

\begin{abstract}
The development of the new era calls for the acceleration of the implementation of Internet power strategy, Internet Plus action plan and big data strategy to effectively promote the realization of the goal of building a powerful modern socialist country. Among them, modernization of tax management is the most important and fundamental component,

is indispensable to

and it

establish

tax-concerned information cooperationand sharing mechanism which plays a supporting role. In the research, the author holds that, first

of

all, scientifically formulating tax-concerned information coopera tion and sharing rules is a prerequisite for optimizing the establishment of the mechanism. Second, building a well-run e-government resource sharing and information exchange platform nationwide is the key to ensure the effective establishment of the mechanism. Third, detailed improvement of the norm of constraint and discipline for the utilization of information concerning tax is an imperative complement and extension for the continued expansion of the role of the mechanism.
\end{abstract}

Keywords-International Tax

administration

cooperation, Tax-concerned information sharing mechanism

According to the report of the 19th National Congress of the Communist Party of China, as socialism with Chinese characteristics has entered a new era, the principal contradiction facing Chinese society has evolved, that is, the contradiction between unbalanced and inadequate development and the people's ever-growing needs for a better life. To this end, adopting an overarching and strategic perspective, the report emphasizes on the more conscious dedication to the trend of the era of reform and innovation. The basic realization of socialist modernization by 2035, and building China into a strong, prosperous, democratic, culturally advanced, harmonious and beautiful modern socialist country by the middle of the 21 st century so as promote the realization of a more equitable. Just and beautiful environment and a higher level of spiritual life as well as eventually enhance the overall development of man and the overall progress of the society.

In the course of this historic change, comprehensively deepening the reform of the taxation system and realizing the modernization of taxation has become an essential component of the overall modernization of China's economy, society, politics, and ecology. In 2013, the State Administration of Taxation had set the goal of basically realizing tax modernization by 2020 , which calls for a stable and strong information system to consolidate the cornerstone of the modernization of tax management and provide conditions for safeguarding and upgrading China's taxation management and its capabilities.

Legal, safe, feasible, and efficient utilization of massive tax-concerned information is the foundation leading to the establishment of a stable and robust tax information system. Against the backdrop of Internet Plus and the community with a shared future for mankind established, managed, owned and shared by all. It has become an important indicator evaluating the level and ability of China's modernization of tax management that the implementation of the tax-concerned information cooperation and sharing mechanism and whether it responds to the new demand of the tax management developing and expanding in the new era.

\section{THE SIGNIFICANCE OF ACCELERATING THE ESTABLISHMENT AND DEVELOPMENT OF CHINA'S TAX-CONCERNED INFORMATION COOPERATION AND SHARING MECHANISM IN THE NEW ERA}

"There is no modernization without informatization." Since the rise of the Internet in the 1990s, the global digital economy has developed rapidly, transforming "from the edge to the center" and exerting a wide-ranging, sustained, and profound impact on all sectors of the economy and society. At the turn of the century, the term "informatization" was officially written in the national planning for the 11th Five-Year Plan. In 
2015, the State Council further proposed Internet Plus action plan serving as a national strategy. In September of the same year, the State Administration of Taxation responded and confirmed the "Internet + Tax" action plan. At present,with the rapid advancement of internet application and innovation around the world, corporate operations, social development, government administration, and international cooperation are confronted with increasingly tremendous changes and challenges. In this case, taxpayers, the general public, governments, and international organizations are all looking forward to more convenient, efficient and civilized tax management and services based on the rule of law. In this critical period of economic and social transformation, the diversity of parties with different interests are growing with various social conflicts rising as well as the way the society is organized and managed to undergo profound changes.

The supply-side structural reform is a long-term systemic project that has been promoted in recent years requiring for efforts of both the supply side and the demand side, streamlining government and delegating power, transforming government functions, and reducing information asymmetry. The priority has been giving to the innovation of information sharing mechanism. Meanwhile, the Internet, big data, and cloud computing have linked together all the tax-concerned activities of parties involved around the "tax-concerned world" and in "taxation countries." Tax-concerned information is filled with every corner of our life and work, affecting the tax benefits of all taxpayers and even countries.

Tax-concerned information consists of broad and narrow senses. The tax-concerned information includes all information related to tax in the economy and society, narrowly speaking; it refers only to information closely related to taxpayers utilized by tax authorities in tax management activities. With consideration of the broad sense, the author believes that only in the broad context, can people take into full account of various interactions of the tax-concerned information and its utilization in international tax cooperation.

Currently, the significance of speeding up the establishment of the tax-concerned information cooperation and sharing mechanism is mainly reflected from the perspectives as follows:

A.It will help to greatly improve the scientificity and feasibility of the taxation reform, as well as the top-level design of taxation management and decision-making.

From the perspective of the new institutional economics (NIE), the reform of the tax system is the process in which the government and the public adapt to the changes in the society and economy. A range of institutional mechanisms (including the formal and informal systems as well as the implementation characteristics of the system) must comprehensively complement each other and optimize to change the attitudes and actions of relevant tax-concerned entities, reducing the cost of the reform, improving the well-being of the people, and successfully achieving the overall goals and effectiveness of the reform.

Tax-concerned information cooperation and sharing mechanism is an implementation mechanism of the tax system. Due to the lack of innovation on building effective, feasible and complementary

taxation management mechanisms, it is difficult to implement the reform of the tax system better. In the crucial stage of keeping in line with the new normal of economic development, pushing forward the supply-side structural reform, and further implementing strategies of streamlining government, delegating power and transforming government functions. Moreover, the development and innovation of the tax-concerned information cooperation and sharing mechanism is the priority of primary importance to reduce information asymmetry and its possible negative impacts on tax legislation and decision-making of the reform. According to the information released about the management of property rights of information resources in China, $80 \%$ of information resources are now managed by government departments[[1]]. In 2017, tax revenue under China's general public budget totaled 143.4 billion yuan (RMB), accounting for $83.7 \%$ of the fiscal revenue, and $17.45 \%$ of the GDP for the year. The relevant massive tax-concerned data must integrate and interact organically with tax revenue to ensure safe, unified, efficient and integrated exploration and analysis as well as the improvement of utilization efficiency. Only in this way, can the mechanism help to optimize and perfect the socialist taxation law system with Chinese characteristics in the new era to provide extensive and far-reaching support for making more scientific and democratic significant decisions on China's macro-economy.

B.It is conducive to establish a scientific and rigorous tax collection and management system as well as an efficient and uncorrupted tax administration system to improve the quality and efficiency of law enforcement of China's taxation administration in the new era.

The application of big data and cloud computing technology in the modern administration of taxation marks a huge challenge and has impacts on governments and tax authorities accustomed to the administrative management systems and means under the traditional bureaucratic governance structure system. The improvement of the national governance system and capability in the new era inevitably requires major changes of governments themselves in line with the age. In response, hundreds of thousands of professionals working on the taxation system have become the "leaders" of the reform. Since reform and opening up policy was introduced in the 1980s, they have continuously innovated, practiced, and forged ahead to make 
progress in tax service, invoice management, tax informatization, and application of technology. The past years have seen the most typical model-the achievements made in tax management with information of the Golden Tax Project which has not only promoted the process of modernization of tax management in China but also become "one of the basic projects of the structural reforms on government administration and politics"[[2]]. Scientific and technological innovation has led to the innovation of the system of tax collection and management information as well as other related mechanisms, and served to accelerate the further development of the structural reform of tax administration (such as the determination of the structural reform plans for the collection and management of national and local taxes, and the introduction of the cooperation work norms for national and local taxes, etc.). But up to now, admittedly, China's tax reforms are inadequate in the application of big data of tax[[3]]. Besides, more reforms have yet rooted out the government-centered bureaucratic organization and management of government (tax) affairs when the deep integration of information technology and tax service remains a problem unsolved, hindering the in-depth development and utilization of tax-concerned information.

In the second decade of the 21st century, China has entered the critical stage of deepening reforms. The evaluation of whether China improves its international capability of managing tax-concerned information in the new era involves several aspects, such as how to fundamentally establish a mechanism forging forward with the tax system, adapt to the demand of an in-depth analysis of source of taxation, and consistent with the needs of taxpayers and even changes in social development, how to ensure the safe and stable operation of tax-concerned information through the coordination with scientific and technological innovation and the joint administration with the government, the market, and the society, and whether the country has its controllable core technology and an internationally advanced tax-concerned information management and application system which will help the delayering of government authorities, efficiency of function allocation as well as more transparent, efficient, and clean operation. Among them, the forward-looking design as well as orderly and effective operation of the tax-concerned information cooperation and sharing mechanism based on the establishment of a stable and powerful information system is a precondition for a modern taxation system with a scientific and rigorous tax collection and management system, and an effective and uncorrupted organization system as its key. Only in this way can the government accelerate the creation of a fair, equitable, legal, civilized and high-quality tax environment.

\section{C.It will help improve the quality and convenience of the tax service system.}

"Service" is the most basic and core duty of the government.

Since the 1980s, the ascendant global tax reforms have allowed information technology to intervene, not only impacting and triggering a new round of technological innovations and improvements in tax-concerned management but also stimulating the transformation of the ideals of taxation management as well as the collection and management model. It has turned out that "service administration is the theme of future public administration." As the world's largest economy, the United States implemented the institutional reform and restructuring act in 1998, stating "providing services with the highest quality for Americans by helping taxpayers understand and perform their tax obligations and by making the tax law fair to all taxpayers" as the mission of modernizing US tax management and wrote it down in the IRS's taxation strategy plan for implementation. In New Zealand, the government directly named the taxpayer charter as the "Client Charter" to clarify the rights and obligations of all parties. In the 21 st century, China has adopted a detailed revision of the corresponding provisions of the Tax Collection and Management Law to legally stipulate the customer-oriented taxation which effectively meets the legitimate needs of taxpayers, eases their tax burden, and protects their legitimate rights and interests. The government always considers the continuous improvement of tax compliance and taxpayers' satisfaction as the primary criteria for measuring the performance of tax service provided by tax authorities. Prominent achievements have been made in tax service, including the "Tax service for the convenience of the public-- Spring Breeze Action" since 2014, the gradually optimizing National Tax Service Regulations for All Authorities and National Tax Collection and Management Regulation through several revisions which streamline tax-concerned professional services as well as the collection and management process.

At present, most countries have already made the e-government a strategy enhancing national strength and comprehensive international competitiveness. The e-government practice highlights the "public-orientation" in the constant reform and practice as well as the deepening of understanding. "The borderless, distributed, open and sharing, connected, and service-oriented features of Internet technology" [[4]] bring unprecedented changes to this huge global technology platform and advance the governance reform of "Internet + Services." Impacting through the development planning system and implementation mechanisms such as of such as tax-concerned information service sharing mechanism, massive cross-industry, cross-region, and cross-application data and resources are used to effectively and 
orderly maintain the tax-concerned interactive exchanges of the parties involved in the society, adjust the improvement of tax law enforcement services in a timely manner, and promote the establishment of a national cloud computing platform for government affairs based on tax-concerned information cooperation and sharing.

\section{D.It is conducive to strengthening} international cooperation of tax collection and management to make open, shared and mutually beneficial international taxation cooperation to a higher level.

The further development of the new model of public management against the backdrop of "Internet Plus" has provided new conditions and platforms for tax cooperation among various countries. In recent years, China has also achieved rapid development in this area. In 2013, the signing of the Multilateral Convention on Mutual Administrative Assistance in Tax Matters as amended by the 2010 Protocol marked the full participation of all G20 members which then made it gradually become the new standard for international taxation cooperation and collaboration around the world. Meanwhile, the protocol has also promoted China's further utilization of international tax administration collaboration to improve the tax services as well as collection and management quality for cross-border taxpayers, serving to create a fairer and more transparent international tax environment.

In June of the same year, G20 entrusted OECD to release and promote Base Erosion and Profit Shifting Action Plan (BEPS Action Plan for short) which marked the joint efforts made by G20 countries to fight against international tax evasion and avoidance as well as jointly take major measures to build the international tax regulation system and administrative cooperation mechanism favorable to the international economic growth [[5]] . At present, the BEPS Action Plan contains fifteen major actions in five categories, including addressing the challenges posed by the digital economy, reshaping the existing taxation agreements and international rules of transfer pricing, improving tax transparency and certainty, and developing multilateral taxation tools to promote the implementation of the action plan. All the actions are aimed at resolving the new problems of international taxation brought about by the rapid development of economic and social globalization.

In September 2014, Chinese government pledged at the G20 summit that China will implement the automatic exchange standard for tax-concerned information of financial accounts formulated by OECD which was entrusted by G20 for the first time in September 2018 so as to increase the transparency of taxation through strengthening the global tax cooperation and crack down on tax evasion and avoidance by overseas accounts. So far, building transparent international tax system with this standard as the core is in the ascendant, and the global tax network platform with "long arms" has been initially established.

In the new era, upholding and developing the idea of "great country taxation," China will better display its image as a major responsible country to enhance its influence and make its voice in the international taxation community. To further create a fair, transparent, open, inclusive, mutually beneficial and win-win international tax and business environment, domestic and international interconnection must be achieved to jointly create and deepen the tax-concerned information (intelligence) exchange system. Every party is expected to fulfill its corresponding international tax-concerned obligations to well prepare for the effective implementation of the 3D strategy(detect. deter 、 discourage) adopted t cross-border tax evasion and avoidance regarding laws, information technology, data utilization as well as effect evaluation and improvement.

\section{TO ACCELERATE THE CONSTRUCTION OF CHINA'S TAX-RELATED COOPERATION AND SHARING MECHANISM IN THE GLOBAL VISION}

According to January 31, 2018, China Internet Network Information Center ( CNNIC) 's "41th China Internet Development Statistics Report" showed that by December 2017, the population of Chinese cyber citizens reached 772 million, and the penetration rate reached $55.8 \%$, which exceeded the global average $(51.7 \%)$ by 4.1 percentage points and exceeded the Asian average (46.7\%) by 9.1 percentage points. These data indicate the vigorous development of the Internet industry in China and the tremendous impact and changes brought about by mobile Internet on China's social life.

In today's world, in the process of continuous restructuring of global value chains, the global profit is more than $50 \%$ involved in international trade. Under the existing international tax rules system, the cross-border flow configurations of related production factors are distorted through tax planning, the international tax fairness facing with a huge challenge and the international tax order is seriously threatened. Therefore, all countries must actively promote the tax system reform, build multi-lateral taxation cooperation and information sharing system mechanisms for external agencies and strengthen the efforts to crack down on the international tax avoidance behavior of sanctions. It lays a practical and efficient information system's foundation for optimizing national and international tax collection and management system and promoting China's reform, opening up and tax modernization. At present, we should focus on the following aspects:

\section{A.Setting up rules for cooperation and sharing of tax information scientifically is a prerequisite for mechanism}

In 2015, the summary of all 15 output results of the BEPS action plan issued by the OECD and China's tax reform in the 
process of comprehensively deepening the reform and improving the national governance system and governance level indicated that existing international tax rules system must be reshaped to ensure the fair and effective international taxation and promote international trade and cooperation. Among them, the international tax allocation activity should be based on the principle of "Matching with actual economic activity and value creation", with the focus on avoiding double taxation, to establish the starting point for the establishment of a new international taxation cooperation system, and to measure tax compliance and satisfaction in various countries. International tax collection and management cooperation does not lead to double taxation, aggravate taxpayer compliance with tax laws or block legitimate cross-border trade; it should also effectively eliminate international double taxation, conform to and promote the development of economic globalization.

As the basis of tax-related interests within the sovereignty of a country, conflict resolution and international cross-border tax information acquisition and value-added use of the three-dimensional network basis, is based on the extensiveness, dynamic complexity, and speed of tax-related information, and the highly relevant characteristics of multi-level stakeholders, as well as the shift from one-way management to two-way interaction in China's social governance model, from offline to offline convergence on the line, from the simple government supervision to more emphasis on the social coordination of governance changes. The content of tax-related information cooperation and sharing mechanism and its control model should be determined by balancing the interests of all parties, statutory compliance after consultation, and safe and efficient utilization of the basic principles. The government can concentrate its efforts on handling major events, planning and formulating and implementing afterward. And taking the central government as the leading force, we actively improve the national integrated taxation database and crucial cross-border tax database that are conducive to the promotion of public tax values ?6?7?6?7and public interests. By the "Administrative Measures for Tax Information Inquiries" established by the State Administration of Taxation in 2016, the legislation unified and standardized the procedural rights and obligations of Chinese society to obtain tax information. And it adheres to the dynamic, open, safe, legal, and standards-based approach to the safe and effective use of tax-related information. The third-party provision of tax-related information acquisition management system must be vigorously strengthened. There should be a dedicated inquiry and management agency responsible for providing inquiries and management matters which scientifically and strictly control the in-depth analysis and utilization of tax-related information from the source, taking into account both the public interest, different taxpayer group interests and personal interests into taxation. There should facilitate the coordination of tax-related policies and practices, achieve different interests, avoid conflicts and affect the stability of economic and social order.

\section{B.Constructing a smooth e-government resource sharing and information exchange platform for the entire society is the key to ensuring the effectiveness of the tax-related information cooperation and sharing mechanism.}

In 2015, the State Council announced the "Action Plan for the Promotion of Big Data Development," which made clear the goal of achieving the full coverage of the data sharing and exchange platform at the central government in 2018. A series of important basic information systems, such as Gold Tax Project, Government Finance Management Information Systems and Golden Gate Project, which involve the development of the national economy, and the people's livelihood and the implementation of policy, will be shared and exchanged through a unified platform. After that, as the country's e-government governance capacity and demand multiple, and taxation governance modernization levels increase, the realization of cross-sector tax-related information cooperation and sharing will surely become a new driving force for the optimization and development of China's economic structure and a new way to improve government's governance capabilities.

In the process of deepening reforms, China should strengthen Internet thinking and make use of the advantages of Internet's flattening, interactive and shortcut to break the state of self-closed operation and management of the "self-sufficient" data of the traditional tax information flow and develop a seamless government public administration tax-related information platform under integrated governance. With the reform implementation of the registration system of " five certificates in one" in the past two years, and the rapid popularization of China's unified social credit code infrastructure system, the unified standards of enterprise registration and data exchange will have a smaller gap with a seamless connection of the whole process of public administration. The sharing of information will gradually be satisfied. With the continued implementation of the "Outline of the Social Credit System Development Plan (2014-2020)", the achievements of China's tax credit system are changing with each passing day. In 2020, China will establish a basic system of laws and standard system, and basically complete a credit system that covers the entire society based on the sharing of credit information resources. By then, the taxation awareness and credit level of the whole society, including tax integrity and compliance with laws, will be greatly increased. The efficiency of the use of tax-related information will be greatly improved in different sectors, regions, industries, and even International efficient and safe flow, combination and value-added. It will have an extremely important impact on enhancing China's tax transparency, comprehensive competitiveness, and promoting a more orderly and open world, fair and just, cooperative tolerance and co-governance sharing. 
In this process, the "Provisional Measures for the Administration of the Sharing of Governmental Information Resources ", promulgated by the State Council in 2016, shall be strictly followed, the amendments shall be made to the "Regulations on Disclosure of Government Information", and "Interim Measures for the management of taxpayers' tax-related confidential information". Due to the special role of tax-related information, relevant security measures for big tax data should be improved according to international standards (such as FTA standards), and the use of financial tax information should be continuously improved.

By formulating relevant work regulations or guidelines for tax account information management of financial accounts, it is necessary to clearly classify the information management authority, to effectively identify and prevent the risk of tax-related information disclosure through the compliance and development of due diligence procedures, and to pay close attention to the development of taxpayer classification and classification tax risk analysis application system. The increase of compulsory disclosure and voluntary tax disclosure rules in the revision of the legal system will enhance the ability of the personnel of the practice department to obtain in the design and improvement of China's tax collection and legal management system. Relying on tax-related information to improve tax administration ability and reducing the ability and flexibility of management risk will be more targeted to solve tax base erosion and profit transfer.

C.Refining and perfecting the tax-related information use restraint discipline standard is the necessary supplement and the expansion of the role of the tax-related information cooperation and sharing mechanism.

"Without information security, there is no national security. " Under the sharing of massive tax-related information, the value-added use process will inevitably face great security risks. On the one hand, it comes from information asymmetry or disclosure, on the other hand, it comes from attacks by hackers, etc. This hurts the tax benefits of all parties. Therefore, the construction of China's tax-related information cooperation and sharing mechanism must be highly consistent with the requirements for the use of modern information security supervision. In addition to continuously improving tax-related information security measures in terms of workflow and information technology, stepping up trials and summarizing good tax risk portrait analysis, we must also improve the dynamic monitoring mechanism for cross-border capital flows. And we should comprehensively use the "blacklist" system of tax violations and a joint disciplinary mechanism to promote the effectiveness of the social disciplinary incentive and dishonesty combined disciplinary mechanism.

In the process of international tax collection and management cooperation, establishing a feedback mechanism for financial account information exchange and developing a multinational enterprise profit level monitoring system will help to improve the quality of international exchange and use of tax information and enhance the timeliness, accuracy, integrity and effectiveness of financial account information exchange among partner countries. In addition, in order to ensure that the BEPS action plan does not bring tax uncertainty or double taxation to the compliance taxpayers, it is necessary to create and continuously optimize the more effective international tax dispute settlement mechanism.

At present, China is expanding the openness of economy at a wider range, wider scope, and deeper level. Economic globalization has enabled China to further increase economic and social exchanges and cooperation with other countries and regions in the process of increasing openness. Accelerating the establishment of safe and efficient operation, transparent and fair tax-related information cooperation and sharing mechanism is an important basic condition for upgrading the modernization level of China's taxation administration and the country's soft power. It is even more important for China to deepen cooperation in international tax collection and management, give better play to the role of a "responsible big country." It is the only way to create a brand and lay a global tax network with international tax cooperation and exchange.

\section{REFERENCES}

[1] Zhou Min:Building a Shared Platform,Innovativing Mechanism Systems,Improving the Ability andLevel of Government Information Resources Sharing

[EB] .http://www.xinhuanet.com/info/2016-09/21/c-135702887.htm (In Chinese)

[2] Hua Tao.Cooperative Governance in Cyberspace:Expansion and Reconstruction of Governnental Governance ( $\mathrm{J}$ ) .Public Administration.2017(2).p.34 (In Chinese)

[3] Sun Cunyi,Tan Ronghua.On the Selected Path to Promote the Tax-related Big Data Analysis via the "Internet plus Tax Management" [J] .Taxation Research Journal,2017 ( 3 ) ,pp.9-13 (In Chinese)

[4] Xie Bo Feng,Form the Tax Computerization to Internet Plus Tax-Retrospect and Prospect of the Application of Information Technology on Tax Administration in CHINA $[\mathbf{J}]$.Taxation Research Journal,2017 ( 3 ) ,pp.14-18 (In Chinese)

[5] Chinese Association of Certified Public Accountants.Tax Laws ( $\mathrm{M}$ ) .China Financial and Economic Publishing House,2017.pp.427-431（In Chinese） 